\title{
Implementation of Multidimensional Environmental-Economic Collaborative Management in IoT Environment
}

\author{
Biao Geng, ${ }^{1}$ Guojun Yuan, ${ }^{1}$ Daoning $W{ }^{2},{ }^{2}$ Enquan $S h i,{ }^{3}$ and Yang Zhou $\mathbb{D}^{1}$ \\ ${ }^{1}$ Economical \& Management College, West Anhui University, Lu'an 237012, China \\ ${ }^{2}$ Chengdu Institute of Biology, Chinese Academy of Sciences, Chengdu 610041, China \\ ${ }^{3}$ Shangqiu Normal University, School of Information Technology, Shangqiu 476000, China \\ Correspondence should be addressed to Yang Zhou; 10000100@wxc.edu.cn
}

Received 7 December 2021; Revised 22 December 2021; Accepted 23 December 2021; Published 25 January 2022

Academic Editor: Tongguang $\mathrm{Ni}$

Copyright (C) 2022 Biao Geng et al. This is an open access article distributed under the Creative Commons Attribution License, which permits unrestricted use, distribution, and reproduction in any medium, provided the original work is properly cited.

The Internet of Things (IoT) has gotten a lot of attention as a next-generation Internet application, and its realization, which connects things, people, and things, is the focal point of a new round of high-tech competition around the world. Network technology has a significant impact on people's lives today, thanks to the rapid development of the Internet, and the Internet of Things (IoT) is a technological innovation of the times that promotes the development of information technology. The Internet of Things has given the logistics industry a new lease on life, allowing it to grow more intelligently. The modern logistics industry is a modern service industry that includes transportation, warehousing, freight forwarding, information, and other industries, and it is very important. This paper examines the technical system of the Internet of Things and the logistics economic management mode, as well as the impact of the Internet of Things on logistics economic management. A multidimensional collaborative management model of environment and economy is proposed, based on the background of IoT. It has laid the groundwork for the IoT's application and development in the logistics economy.

\section{Introduction}

The world is linked by electronic communication technology. It is possible to connect things thousands of miles apart, which has greatly aided the advancement of human communication [1]. The traditional logistics system has proven insufficient to meet today's development needs. The logistics industry's previous business model is changing. The state has previously paid attention to the logistics industry, which is represented by railway [2]. In recent years, IoT technology has aided the logistics industry's informatization, automation, and integration, as well as its overall development. In the process of information technology development and logistics service diversification, modern logistics collaborative management is a new logistics management problem $[3,4]$. New problems in logistics management have emerged as a result of the Internet of Things. In this case, the logistics industry should seek out new approaches.

In recent years, China's Internet technology is constantly improving. Internet technology has gradually changed to
IoT technology. IoT technology has broken the traditional Internet virtual environment. The IoT can combine the network and objects, so that the real and intelligent selfperception can be connected with objects, so as to achieve the purpose of global interconnection. As the main application of the next-generation Internet, it has received extensive attention [5]. At present, the development of Internet technology has gradually transformed logistics into the IoT. Through the development of IoT technology, the logistics industry and Internet technology are continuously integrated [6]. The logistics industry needs to adapt to the new features and seek the best method for the transformation of the logistics industry in the IoT [7]. In the logistics industry, the use of modern IoT technology can have a strong impact on the traditional logistics economic management, reestablish the recognition of logistics enterprises for science, technology, and information, improve the intelligent monitoring and management of logistics enterprises, promote the sharing of information resources among logistics enterprises, and finally achieve the purpose of win-win. 
The logistics industry will usher in a comprehensive innovation against a modern backdrop. The use of IoT technology in the logistics industry can help to improve the logistics industry's operational efficiency, improve the quality of logistics work, and aid in the development of China's logistics industry [8]. IoT is a technology that perceives, analyzes, controls, and manages goods using integrated technologies such as intelligent sensing systems, computers, and the Internet. The IoT's emergence and development will inevitably bring certain opportunities and convenience to the development of modern logistics, particularly in the visualization of logistics transportation, intelligent transportation, and logistics information networking, where the benefits of the IoT are clear [9]. The current cloud computing expertise can largely stabilize IoT expertise, which can improve logistics economic management work efficiency and reduce the likelihood of problems at work [10]. This paper introduces the multiagent collaboration mode of modern logistics network layer under the cooperative game and the multidimensional collaboration classification of modern logistics, starting with IoT-related knowledge. It was decided to create a multidimensional environmental-economic collaborative management model. Information collaboration can significantly improve the efficiency of the logistics economic system and bring more economic effects, according to simulation and numerical experiments.

\section{Related Work}

Literature [11] expounds management synergy from the perspective of economic management. Zhou and Yuan [12] pointed out that the synergy between various social departments is not strong, resulting in the low efficiency of social management. Therefore, in order to improve the efficiency of social work, a mechanism of social synergy must be formed. The research on collaboration in [13] is specific to the management level. Literature [14] holds that collaboration is a simple combination of individual parts, which forms the overall state and business performance of the enterprise. Literature [15] regards the whole supply chain as an evaluation subject and believes that it is more practical and scientific to establish a group rather than a single evaluation index. Literature [16] uses economics to analyze and define synergy: the value of the enterprise as a whole is greater than the simple sum of individual components, and the effect of collaboration is far greater than that of individual operation, which is the reason for the emergence of economic scale. Literature [17] believes that collaboration can maximize the utilization of resources. Resources can be divided into two types: one is entity resources. Literature [18] pointed out that, in the face of the rapidly changing market environment, enterprises need to seize the fleeting market opportunities and effectively integrate intellectual resources. It is necessary to form a mechanism-management synergy. Literature [19] proposes that management collaboration is not a natural selection process. In order to ensure the smooth operation of the enterprise system, managers understand the development of the enterprise system and the changes of the environment from multiple angles. This behavior process aims to explain why enterprise systems need management collaboration. Literature [20, 21] believes that a good measurement standard should involve these key elements of the logistics process: time, distance, and capital. Literature [22] believes that there are many ways for enterprises to realize collaborative benefits, such as business behavior, information sharing, information flow, and so on. However, it does not mean that these means can completely solve the problem of synergy. The root cause is that sharing is limited. Only enterprises with innovation ability can truly realize synergy. Literature [23] believes that, with the wide application of Internet technology, collaborative logistics has become a new business model. This model focuses on the integration and unification of the overall value, attaches importance to the information sharing and collaborative operation between upstream and downstream partners of the supply chain, and forms a good business operation network environment by establishing efficient collaborative mechanisms and norms. Literature [24] pointed out that the information that can be shared is not only inventory and order information, but also sales information. Literature [25] analyzes the collaborative operation of regional logistics clusters. Literature [26] proposes a negotiation based method to solve the distributed project scheduling problem. It is pointed out that the information sharing can be improved by sharing the flexible information of enterprise dispatchers and improving the concentration and scheduling quality. Literature [27] proposed three modes of cooperative operation. According to the different degree and relationship of node members, it can be divided into point chain collaboration, line chain collaboration, and full chain collaboration. Literature [28] pointed out that qualitative analysis is the focus of current research, and there is a lack of discussion on quantitative research such as system collaboration level, system collaboration mode, and collaborative system construction. This paper studies the significance of multidimensional coordination of modern economy under the IoT system. Whether it is theoretical analysis or practice and application, a complete set of scientific theories and management methods are essential to guide the successful application of the IoT in the economic field. In this paper, based on the IoT environment, a multidimensional environmental-economic collaborative management model is established to solve the problem of economic management collaboration. Through simulation and numerical experiments, it is proved that information collaboration can significantly improve the efficiency of logistics economic system. The effectiveness of the algorithm is verified by numerical experiments. The results show that the algorithm can bring more economic effects.

\section{Methodology}

3.1. IoT. In recent years, China has developed IoT professional technology, which is an interconnection technology based on computer professional network technology. The Internet of Things (IoT) is a brand-new type of information and communication technology. It is an important 
component of the new generation of information technology as well as a critical stage in the "information" era's development. With the advancement of communication technology, the Internet of Things (IoT) has become an important guarantee for the growth of the logistics industry [18]. Because people can surf the Internet at high speeds on their mobile devices, the IoT technology development platform has a lot of room for growth. With China increasingly focusing on the development of the IoT industry, the IoT industry has emerged as China's primary technology. China's IoT industry grew and matured earlier, and it has now essentially formed a perfect IoT industry system. And the market's development of some fields has begun to take shape.

As the application of the next-generation Internet, the IoT has received extensive attention, and the realization of the IoT, which interconnects things, people, and things, is the commanding point of a new round of high-tech competition around the world. The technical system of IoT includes three levels: perception layer, network layer, and application layer. The sensing layer is mainly used to identify items through sensing devices, collect information data, and transmit data to gateway devices through transmission devices. The network layer will process the received information data to ensure the security and reliability of the data [29]. In the application layer, information is mainly shared across regions, information is analyzed, and intelligent management services under the IoT technology are realized.

The IoT is an information bearing system based on the development of Internet technology, computer technology, and network communication technology. The system can make the modules with independent functions communicate with each other. IoT technology mainly realizes the connection between objects through infrared positioning technology and Global Positioning System (GPS) technology and uses Internet protocol to combine the Internet with actual objects, so as to realize information sharing. In recent years, China's communication technology is also constantly improving, because today's mobile devices can use the high-speed network to access the Internet, so a lot of mobile device users have been increased, which directly shows that the opportunity of the IoT is coming.

\subsection{Application of IoT Technology in Economic Management} Industry. Perception technology, network communication technology, identification technology, system framework technology, security and confidentiality technology, and so on are all part of the IoT, which together form a massive technical system. The Internet of Things (IoT) is a new era information technology term that denotes the start of a brand-new information era. The Internet of Things (IoT) technology realizes the connection between things, and its core technology is the Internet, which it extends and expands in a sense, with the goal of expanding information exchange to include the exchange of things. In the logistics industry, the Internet of Things is primarily used in the technology of automatic bar code acquisition. The visual intelligent system can help different departments coordinate and unify, rationally allocate logistics processes, and improve the timeliness of logistics management, as well as improving the operational fluency and efficiency of transportation management, warehouse management, and customer information service management. Under the IoT, logistics economic management should create resource codes within logistics units so that logistics resources can be managed in a unified manner, and the authenticity and accuracy of resources must be ensured during the resource collection process. The Internet of Things can be used to create a visual logistics intelligent management system. To ensure that the circulation of articles is transparent and safe. Figure 1 depicts the visual intelligent management framework.

In the traditional logistics management, due to the influence of road, geographical location, and other reasons, the information collection ability of goods is limited, and it is difficult to realize all-round tracking of logistics information. However, the Electronic Prism Collimator (EPC) tag of the IoT has solved this problem. In the aspect of logistics economic management mode, with the rapid development of high technology, quota management mode has emerged, which has advanced management concepts and policies and is widely used in the logistics industry. The management system of quota management mode can promote the rapid development of logistics economy. Besides the quota for product delivery and storage, the comprehensive management of products also needs quota, so as to further clarify the consumption produced by products reaching customers and make the quota management mode of logistics enterprises exert the greatest benefits, thus bringing more economic effects.

Using supply chain management mode, logistics management can reduce transportation pressure and operation costs. The rest can be outsourced to other companies as long as businesses carefully build their own core industries. It can improve not only execution efficiency, but also customer satisfaction, achieve zero storage, and promote the maximization of logistics enterprise benefits in this way. The development of logistics enterprises will be more efficient and long-lasting if comprehensive logistics management capabilities are integrated.

The Internet of Things (IoT) has the potential to improve economic visualization. The most important point to remember during the practical application is to strengthen the integration between IoT technology and logistics economic management, so that the logistics economic management can be completed with greater quality. Electronic identification and analysis of goods can be accomplished using EPC electronic tag technology in logistics, which improves not only the efficiency of screening and distribution of goods, but also the accuracy and speed of distribution. At the same time, the Internet of Things plays an important role in logistics economic management statistics and calculations. It can quickly grasp data and calculate results based on the data, allowing for logistics economic management visualization. 


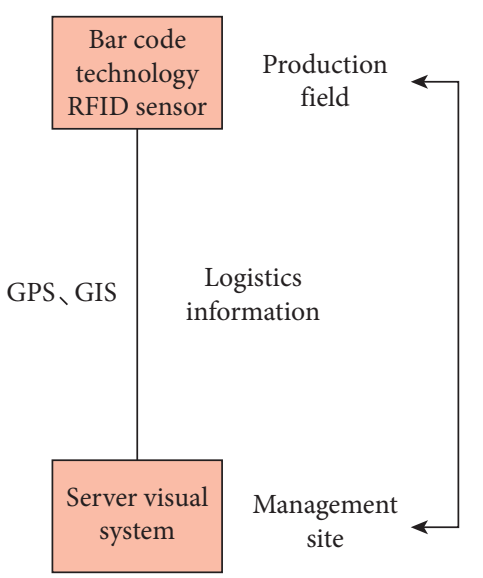

FIgURE 1: Visual intelligent management framework.

\subsection{Economic Management of Multidimensional Collabora-} tive Logistics under the Background of IoT. In the logistics industry, logistics economic management is one of the important works. The main responsibility is to plan, organize, command, coordinate, control, supervise, and encourage the whole process and systematic economic activities of logistics according to the basic economic laws and commodity circulation laws. With the support of IoT technology, the distribution speed of goods and goods information are more rapid and transparent. Goods do not need to stay in logistics companies for a long time, and the flow speed is accelerated. In the context of the IoT, combined with the basic characteristics of rapid logistics, bar code technology is set. When goods are converted or detained, as long as the bar code is scanned, the current transportation status of logistics can be displayed on the network platform through automatic identification. The multidimensional management of contemporary logistics economy has four characteristics. (1) Multidimensional. It includes technology collaboration, information collaboration, service collaboration, management collaboration, etc. (2) Coexistence. Each dimension promotes the others and does not hinder other dimensions. (3) Cooperation. It includes the competition and cooperation of different departments within the enterprise, different enterprises among industries, upstream and downstream supply chains of enterprises, etc. (4) Information sharing. The modern logistics industry is based on information network technology, which has realized a high degree of information sharing and real-time interaction and reduced departmental communication problems caused by information isolation. The multidimensional collaborative classification of logistics is shown in Figure 2.

Modern logistics is facing the necessity of multidimensional collaborative management. Based on the four-tier architecture of the IoT, aiming at the multidimensional collaborative management problems faced by logistics enterprises, this paper defines multidimensional collaborative classification from four dimensions, analyzes the phenomena of logistics enterprises in four-dimensional collaborative classification, and establishes the order parameter equation of logistics system. Suppose the system's cooperative efficiency is $y$, the nonhuman factor is $x$, and $x$ is a function of time $t$. In the initial state of the system, the synergy efficiency is $y_{0}$, and in the lowest synergy efficiency state $x_{d}$, the synergy efficiency is $y_{d}$, and the balance synergy efficiency $y_{i}$; then:

$$
y=\frac{\sin \left(x-x_{i}\right)}{x}+y_{i}, \quad x>0 .
$$

Suppose the system's synergy efficiency is $S$, the nonhuman factor is $\gamma$, and $S$ is a function of $\gamma$, so the formula (1) becomes

$$
S(\gamma)=\frac{\sin \left(\gamma-\gamma_{i}\right)}{\gamma}+S_{i}, \quad \gamma>0 .
$$

So $S$ is the simultaneous function of $\omega, \delta, \varepsilon, \gamma$ and $\eta, \omega, \delta$, $\varepsilon, \gamma$ and $\eta$ are also functions of time $t$, so

$$
\frac{\partial S}{\partial t}= \begin{cases}\beta \omega(t)+S_{01}, & 0<\omega<\omega_{0}, \\ \ln [\delta(t)+1]+S_{02}, & 0<\delta<\delta_{0}, \\ \arctan \left[\varepsilon(t)-\varepsilon_{d}\right]+S_{d}, & 0<\varepsilon<\varepsilon_{0}, \\ \frac{\sin \left[\gamma(t)-\gamma_{i}\right]}{\gamma(t)}+S_{i} & \gamma>0, \\ b \eta^{2}(t)+\sum S_{n}, & \eta>0 .\end{cases}
$$

The macrochange of a complex logistics system is determined by the "synergy" between subsystems, not by the forced action of an external force. Whether it is technology collaboration, service collaboration, or management collaboration, it all starts with information collaboration and has an impact on information collaboration efficiency. The state formed by more than two collaborative requirements that are not of the same type is referred to as multidimensional. Modern logistics is confronted with a wide range of collaborative requirements. Storage space is not only an important index in the logistics industry, but also an important part of logistics economic management. Storage space is primarily used in the logistics link to store goods in the middle of logistics in order to ensure the integrity of goods and improve logistics efficiency during transportation or transshipment. IoT technology can help logistics companies improve their inventory management capabilities by allowing them to control warehouse storage information in real time, allowing them to check leaks and make up deficiencies in real time, and replenishing goods with insufficient storage in real time. The use of IoT technology condenses complex tasks while maintaining a high level of accuracy.

The mobile logistics service requesters and mobile logistics service responders are classified. According to the characteristics of logistics distribution, the nodes are divided into two categories. One is the mobile logistics service requester, represented by $C_{i}$; one is the mobile logistics service responder, represented by $D_{j}$. The trajectory information of the mobile node $C$ in the practice period is expressed as 


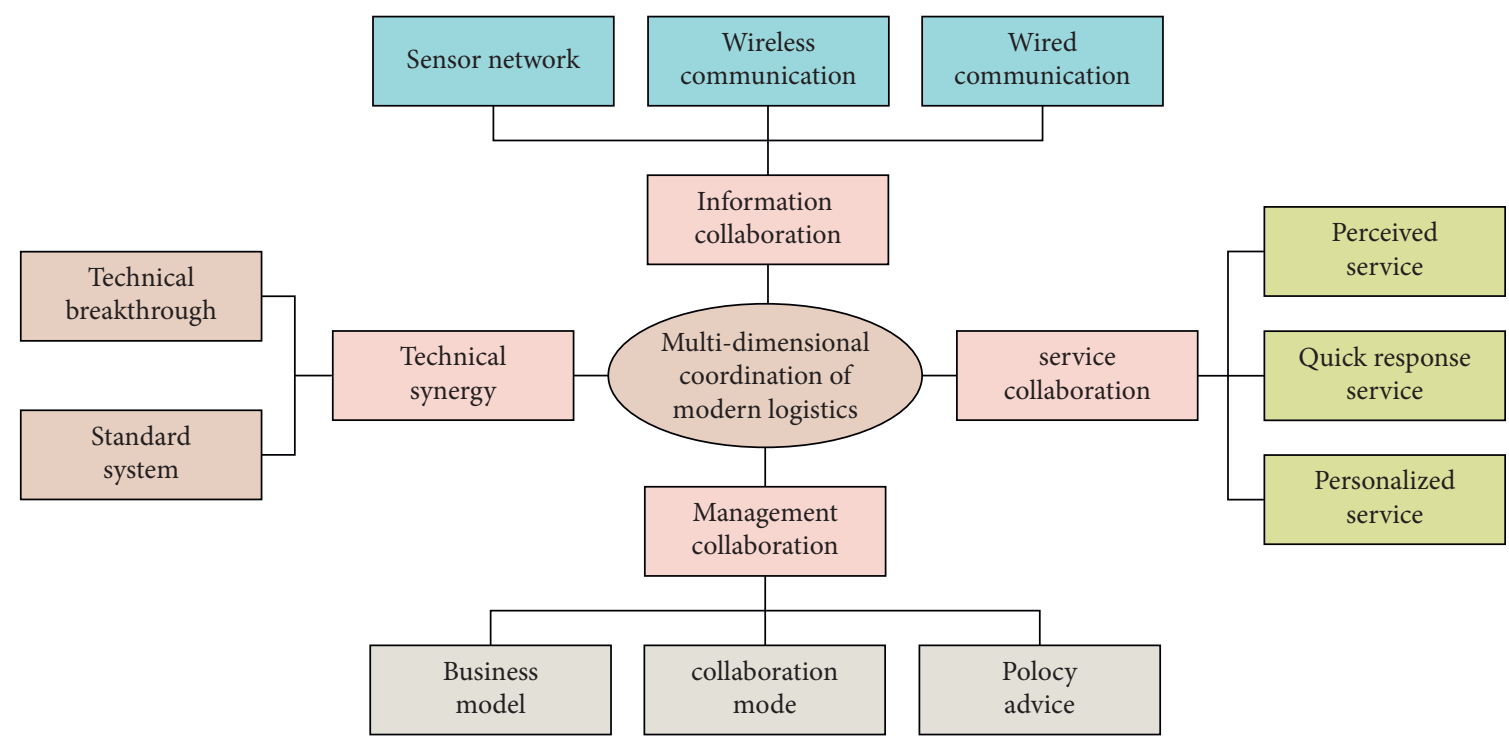

FIgURE 2: Logistics multidimensional collaborative classification.

$G=\left\{\cup_{i=1}^{k} L_{i}, S_{i}, E_{i}, \alpha\right\}$, where $L$ is the location information of the sensing area, $S$ and $E$ are the time when the node arrives and leaves the area, and $\alpha$ is the time threshold, which is used to control the time interval for different nodes to reach the target area. The distance factor between nodes $C$ and $D$ is expressed as

$$
L(C, D)=\frac{\sum_{i=1}^{k} \operatorname{sim}\left(G_{i}(C), G_{i}(D)\right)}{T},
$$

where $T$ is the time period; $\operatorname{sim}\left(G_{i}(C), G_{i}(D)\right)$ is the position similarity function of mobile nodes $C$ and $D$, which reflects the duration of different mobile nodes at position $i$, expressed as

$$
\begin{aligned}
& \operatorname{sim}\left(G_{i}(C), G_{i}(D)\right)=\max \left\{S_{i}(C), S_{i}(D)\right\}-\min \left\{E_{i}(C), E_{i}(D)\right\}, \\
& \text { s.t }\left\{\begin{array}{l}
L_{i}(C)=L_{i}(D) \\
\left|S_{i}(C)-S_{i}(D)\right| \leq \alpha .
\end{array}\right.
\end{aligned}
$$

There is a lot of information related to logistics, and there are extremely high requirements for accuracy and timeliness. In terms of logistics, information mainly includes inventory information, supply information, order information, purchasing information, etc. Controlling information is the most important thing in the logistics industry. Users can know the transportation time, destination, and so on of goods through the mobile phone terminal. This convenient technology can benefit both buyers and sellers. Automatic scanning technology can reduce the loss of goods, improve customer satisfaction, and make logistics and transportation transparent.

$\mathrm{TSP}_{i}$ is used to represent the distribution problem of the $i$ th time slice, and $N$ is the number of cities. $c_{i, j}(t)$ is the weight between city $i$ and city $j$ in time $t, \delta t$ is the sampling period, $\Delta c_{i, j}$ is the change of weight between cities in the sampling period, $T$ is the time period, and $n$ is the sampling times in a period.

The distribution simulation problem based on collaborative information can be expressed as

$$
\begin{aligned}
\operatorname{TSP}(t) & = \begin{cases}\operatorname{TSP}_{1}, & 0 \leq t \leq \Delta t, \\
\operatorname{TSP}_{2}, & \Delta t \leq t \leq 2 \Delta t, \\
\cdots & \\
\operatorname{TSP}_{n}(n-1), & \Delta t \leq t \leq n \Delta t,\end{cases} \\
o \cdot \min d(T) & =\sum_{k=1}^{n} \sum_{i=1}^{N} \sum_{j=1}^{N} c_{i, j}(k \cdot \Delta t), \\
\text { s.t } \Delta t & =\frac{T}{n}, \\
\frac{\Delta c_{i, j}}{\Delta t} & =0 .
\end{aligned}
$$

Equation (6) indicates that the information-based collaborative delivery problem is a combination of different TSPs in different sampling periods. Among them, each TSP can be the same or different. When each TSP $_{i}$ is the same, it becomes a traditional TSP; in the research of this article, they are different. Equation (7) indicates that the goal of completing the delivery is the sum of the target values of each TSP within the time period $T$; that is, it pursues overall goal optimization instead of local optimization. Equation (8) is the definition of the sampling period. Equation (8) indicates that the parameters in the sampling period remain unchanged.

People's production and lives will become more dynamic and refined in the IoT environment, and the way businesses operate will change dramatically. The Internet of Things (IoT) should be studied not only for its application of value-added, but also for the real difficulties and challenges faced by multidimensional collaborative logistics management in the IoT environment. Efforts should be made to incorporate IoT technology into all aspects of logistics management, as well as conduct 
targeted research to increase the value of its application in the field of logistics and provide greater benefits to logistics businesses.

\section{Results Analysis and Discussion}

The composition of IoT technology and logistics industry is relatively complex. By applying the IoT technology to logistics economic management, we can build an informationbased network logistics public information platform. On this platform, customers can inquire about their own goods information at any time, so as to get the latest logistics information. Collaborative analysis is carried out from four levels: perception layer, network layer, application layer, and management layer, and the basic law of collaboration is summarized from the phenomenon of system self-organization and unbalanced phase change. Using quantitative analysis method, the multidimensional collaborative order parameter equation of modern logistics system is constructed.

The Internet of Things has the potential to greatly reduce the phenomenon of asymmetric economic information. It provides a profitable space for commercial banks because of the asymmetric information of small businesses in financing. The Internet of Things accurately and objectively reflects enterprise information, the market economy determines price, the transaction process is intuitive and transparent, and credit and risk assessment data are all open. The asymmetry of small businesses in the financial transaction process can be greatly reduced by analyzing network data. The most trusted technology in the application of IoT technology in logistics economic management is Internet information technology. Information transmission between various devices in the IoT system frequently requires the use of the Internet, which not only improves the rate of data transmission but also improves the efficiency of data processing. Perception technology is the foundation of the Internet of Things, allowing information management systems to "perceive" objects. Figure 3 depicts the market size and market segments of the IoT industry in China's modern logistics field from 2016 to 2020.

Because the application of perception technology has fueled its development, the demand for perception technology synergy has grown even stronger. The Internet of Things (IoT) is a technology that perceives, analyzes, controls, and manages objects using a variety of technologies such as intelligent perception systems, computers, and the Internet. The third information technology revolution is referred to as such. Under normal circumstances, logistics companies deal with a large volume of transactions and cargo transportation every day, so data calculation is a challenge for them. Traditional manual statistics and calculations are prone to errors when faced with such a large workload, and manual calculation is slow, making it difficult to grasp all data quickly. During this time, the IoT system can intelligently analyze goods, such as detailed classification of goods and specific sending areas, to ensure that goods in the same destination are managed and distributed uniformly, ensuring the efficiency of logistics work and the completion of logistics transportation and distribution in the shortest time possible. The real-time traffic information of this simulation system uses the congestion coefficient that obeys the time distribution as the input and divides the urban road traffic into two levels based on the frequency of road use, in order to simulate the real-time traffic information closer to the real situation.

Important path traffic: Urban arterial roads have a large traffic volume, and the road conditions are often in a saturated state. The traffic conditions of important paths are shown in Figure 4.

General route traffic: urban secondary roads and some branch roads. The travel time and frequency of people who use roads are regular, with obvious peaks and valleys in the morning and evening. The general route traffic conditions are shown in Figure 5.

The data in the IoT environment has a wide range of sources, a complex structure, and a large amount of data, and the data will be updated irregularly, so the data in the IoT environment has certain uncertainty. The IoT has certain advantages in mastering data and calculation results. To a certain extent, computers can replace people's work, which can quickly identify and merge logistics circulation characteristics, thus giving birth to barcode technology. "One thing, one standard" greatly facilitates the turnover and circulation of goods. Under the IoT environment, the application of IoT technology is conducive to the development of logistics economic management in the direction of intelligence. There are many independent logistics companies in China, but the information between them can be shared. Because the logistics information is updated very fast and the interaction is complicated, it is necessary to master the rapidly changing information with the IoT technology and increase the communication with other logistics companies.

Because the traditional simulation method takes the distance as the optimization goal and does not consider the road information, it cannot respond to the real-time road information in real time, and its path distance length has not changed significantly. However, when the main roads are congested, the simulation of information collaboration will choose other road sections with a little distance but good road conditions. Therefore, the whole distance will obviously increase during the peak period of traffic congestion. The analysis and comparison between the starting time and the whole distance is shown in Figure 6.

In the IoT environment, logistics development should provide timely feedback on information updates based on changes in various IoT data information, collect changes in information, adapt logistics development to market changes, know the market in real time, grasp the characteristics of big data changes in the IoT environment, and integrate information in real time, so that IoT data information can be integrated. To score the delivery service, receiving service, and online shopping satisfaction of logistics enterprises, choose 30 valid scoring data. The results are shown in Figures 7 and 8 .

The continuous development of IoT economy will impact the traditional economic model, which will make adjustments in business composition, service object, service 


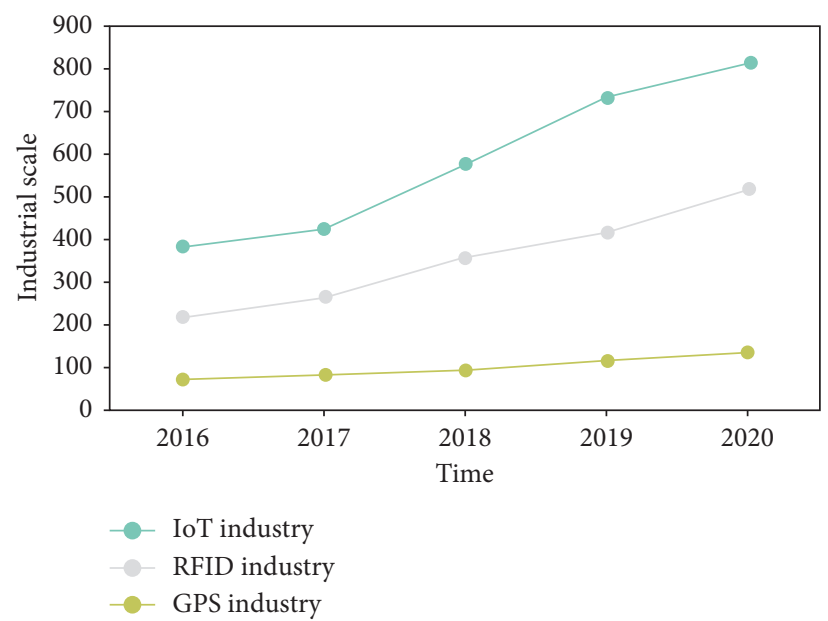

Figure 3: Market scale and growth of various industries in the field of intelligent logistics.

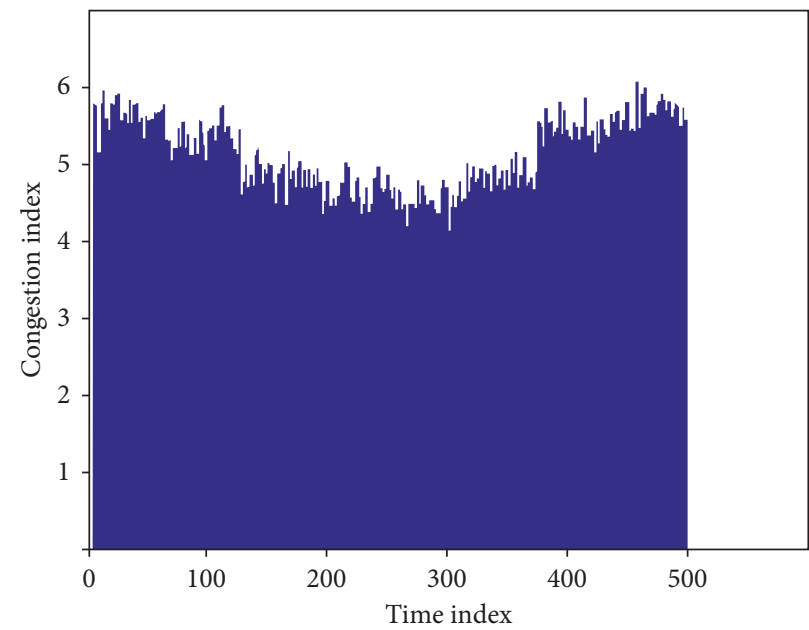

FIgURE 4: Traffic map of important paths.

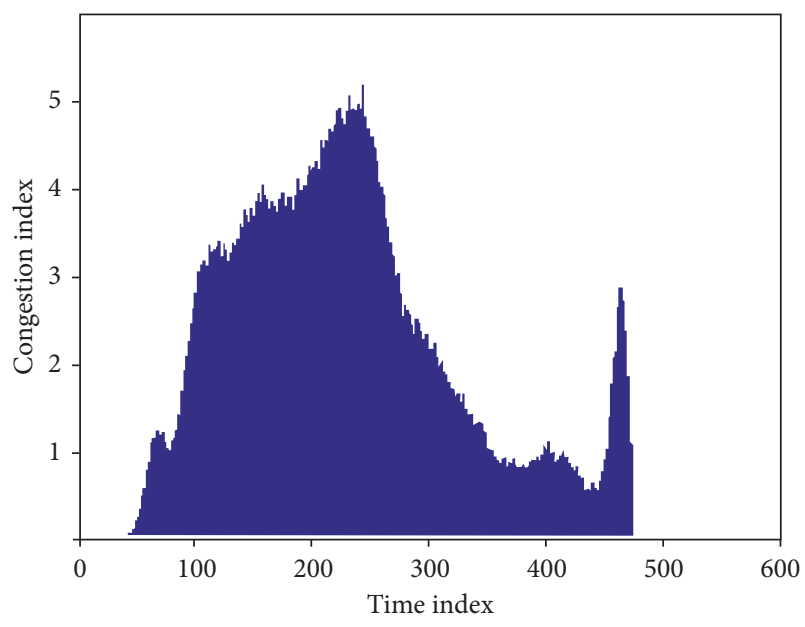

FIGURE 5: General route traffic map.

attitude, and operation mode. Under the current background of the IoT, the logistics economic management has been innovated. Applying the IoT technology to the logistics

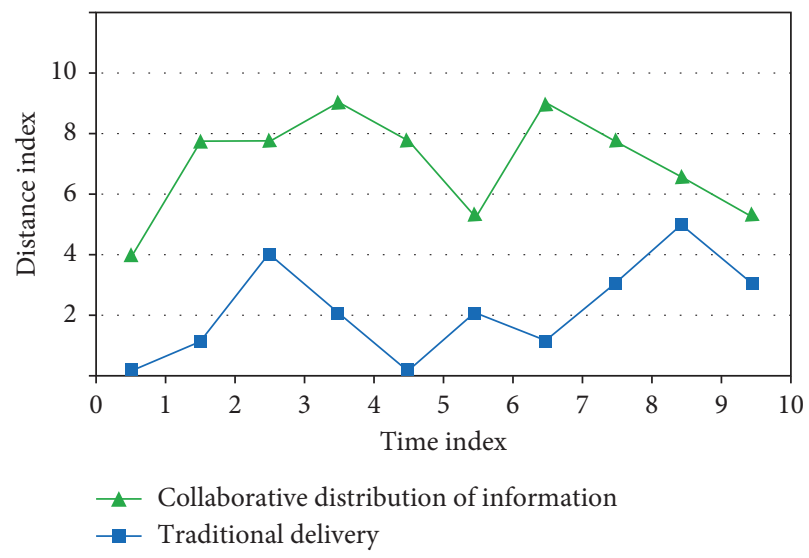

Figure 6: Comparison chart of starting time and full distance analysis.

economic management can effectively improve the quality and efficiency of the work, optimize the service functions of logistics enterprises in all directions, and enable customers to enjoy better logistics services. 


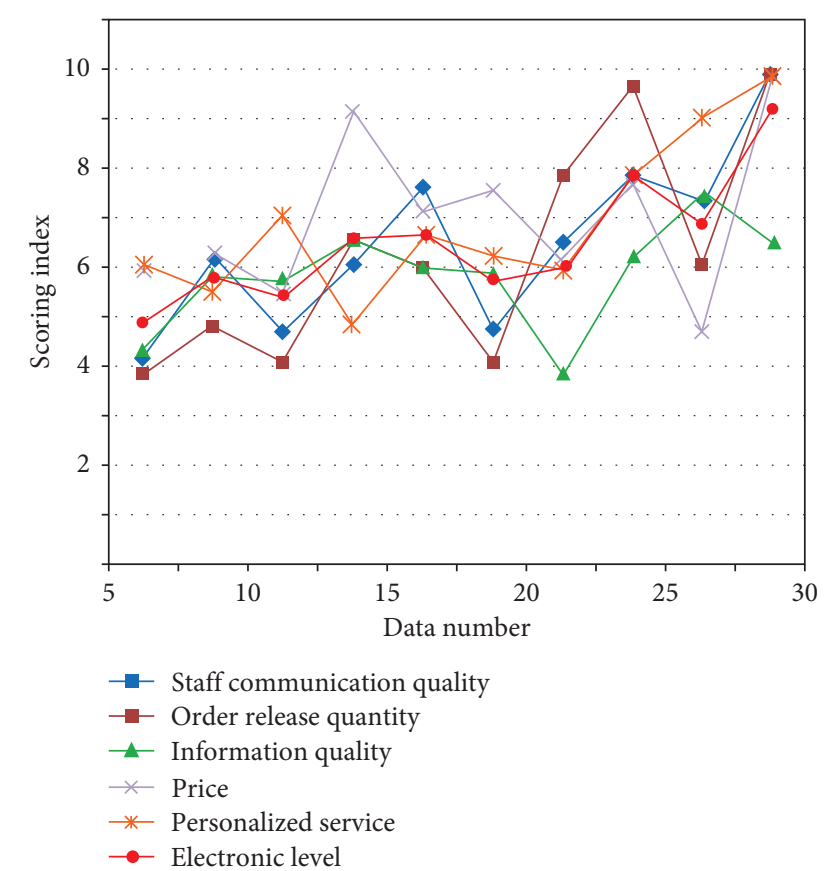

FIGURE 7: Online shopping satisfaction scoring results based on the Servqual scale.

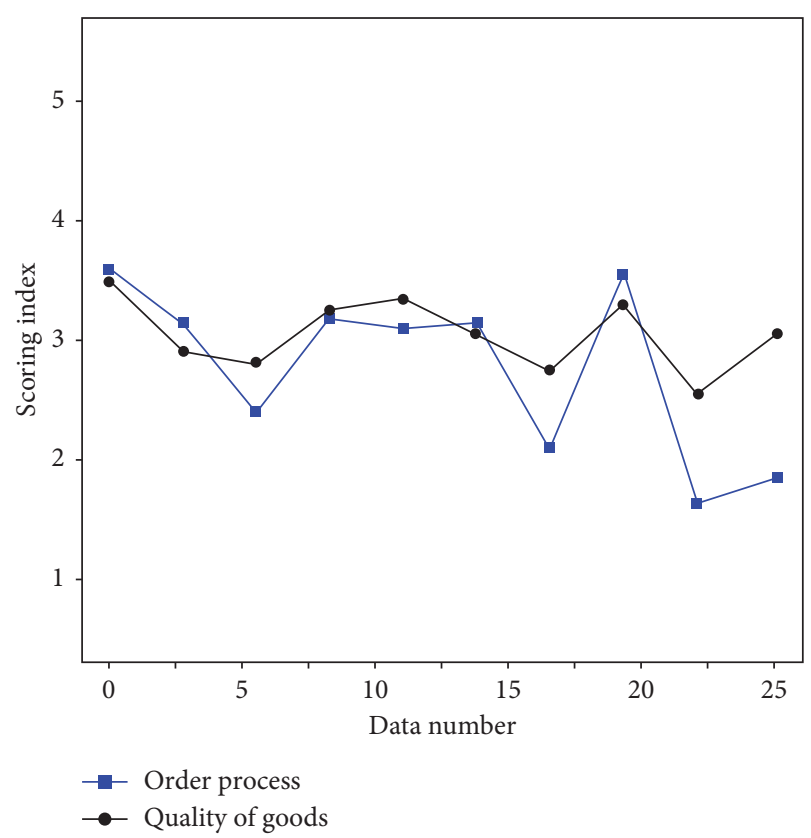

FIGURE 8: The scoring results of the quality of service delivery based on the Servqual scale.

By solving the equation with the algorithm, it is concluded that the information collaboration is the order parameter of the logistics system, which realizes the accurate use of the order parameter to control the fluctuation and balance of the logistics system and build a modern logistics collaborative service platform framework based on serviceoriented architecture and solve the problem of service collaborative management through system platform and quality evaluation and improve the efficiency of logistics economic management.

\section{Conclusions}

The influence of the background of the IoT era on economic industry is revolutionary, and the IoTeconomy is the result of the full integration of computer network communication technology and economic industry. The application of the IoT has improved the running rhythm of modern logistics industry and has also made a revolutionary impact on the multidimensional collaborative management of modern logistics industry. From the current social logistics management process, it has almost subverted the operation mode of logistics. It has promoted the change of economic management concept, operation mode, and profit model and promoted the change of China's economic structure. It has formed innovative forms of financial circulation, such as payment, transaction, and financing, and provided convenience for financial business of all walks of life. Under the background of the Internet age, multidimensional collaborative management of environment and economy is necessary. The development of logistics industry plays a very important role in the transportation of logistics industry and promoting the growth of national economy. Although there are some problems in the IoT economic industry at present, with the supervision and guidance of the state in laws, regulations, and policies, the IoT economic industry will embark on a healthy, sustained, and stable road and become an important part of the driving force of China's economic development. In this paper, based on the IoT environment, the multidimensional collaborative order parameter equation of modern logistics system is constructed, and the simulation and numerical experiments verify that the model can significantly improve the efficiency of logistics system. This paper analyzes the influence of the IoT on the logistics economy, its application, and the problems to be solved at this stage, in order to help promote the development of the logistics industry.

\section{Data Availability}

The data used to support the findings of this study are included within the article.

\section{Conflicts of Interest}

All the authors declare no conflicts of interest.

\section{Acknowledgments}

This study was supported by Key Project of Humanities and Social Sciences, Education Department of Anhui Province, "Research on Audit Risk Behavior Control of Certified Public Accountants" (SK2015A559).

\section{References}

[1] Y. Zheng, Y. Wang, Q. Zhou, and H. Wang, "Eco-environmental IoT framework based on landscape ecology," Acta Ecologica Sinica, vol. 40, no. 22, p. 10, 2020.

[2] G. Liu, Q. Tan, H. Kou et al., "A flexible temperature sensor based on reduced graphene oxide for robot skin used in internet of things," Sensors, vol. 18, no. 5, p. 1400, 2018. 
[3] Y. Zhang, X. Tang, and A. Fan, "The decomposition of human capital efficiency of the internet of things industrial clusters-a follow-up survey of 11 enterprises in Guangzhou economic and technological development zone from 2008 to 2015," Sankei Review, vol. 10, no. 1, p. 15, 2019.

[4] E. Furlan, P. D. Pozza, M. Michetti, S. Torresan, A. Critto, and A. Marcomini, "Development of a multi-dimensional coastal vulnerability index: assessing vulnerability to inundation scenarios in the Italian coast," The Science of the Total Environment, vol. 772, no. 7, Article ID 144650, 2021.

[5] M. Fioriti, A. Mirzoyan, and A. Isianov, "Applying a distributed collaborative MDAO environment to study the power matching of the propulsion system and the on-board electrified systems for advanced regional and short- to medium-range jetliners," Aeronautical Journal, vol. 123, no. 12, pp. 1618-1638, 2019.

[6] H. Asefi and S. Lim, "A novel multi-dimensional modeling approach to integrated municipal solid waste management," Journal of Cleaner Production, vol. 166, no. 11, pp. 1131-1143, 2017.

[7] J. Zscheischler, M. Busse, and N. Heitepriem, "Challenges to build up a collaborative landscape management (CLM)Lessons from a stakeholder analysis in Germany," Environmental Management, vol. 64, no. 5, pp. 580-592, 2019.

[8] M. Babar, F. Arif, M. A. Jan, Z. Tan, and F. Khan, "Urban data management system: towards big data analytics for internet of things based smart urban environment using customized Hadoop," Future Generation Computer Systems, vol. 96, no. 7, pp. 398-409, 2019.

[9] T. Qu, K. Zhang, M. Yan, and Z. Qin, "Linkage decisionmaking and control methods for optimal operation of highly dynamic production systems under the internet of things environment," Chinese Journal of Mechanical Engineering, vol. 54, no. 16, pp. 24-33, 2018.

[10] N. Fan, "Research on the optimization of urban smart community public services under the internet of things environment-comment on "property management work manual"," Forest Products Industry, vol. 336, no. 4, p. 132, 2020.

[11] C.-H. Chen, M.-Y. Lin, and C.-C. Liu, "Edge computing gateway of the industrial internet of things using multiple collaborative microcontrollers," IEEE Network, vol. 32, no. 1, pp. 24-32, 2018.

[12] Z. Zhou and Z. Yuan, "High-efficiency communication receiver design for IoT environment," Journal of Computer Applications, vol. 40, no. 1, pp. 202-206, 2020.

[13] W. Viriyasitavat, L. D. Xu, Z. Bi, and V. Pungpapong, "Blockchain and internet of things for modern business process in digital economy-the state of the art," IEEE Transactions on Computational Social Systems, vol. 6, no. 6, pp. 1420-1432, 2019.

[14] Y. Chen, G. Lee, L. Shu, and N. Crespi, "Industrial internet of things-based collaborative sensing intelligence: framework and research challenges," Sensors, vol. 16, no. 2, p. 215, 2016.

[15] M. Xiao, Y. Li, and W. Li, "Analysis and countermeasures of logistics industry development in the internet of things environment-taking Jiangxi Province as an example," Enterprise Economics, vol. 36, no. 4, p. 7, 2017.

[16] J. Ai, X. Dang, Q. Lv, and C. He, "Research on a full-dimensional equipment condition monitoring system with panoramic functions based on the internet of things," Power System Protection and Control, vol. 47, no. 16, p. 7, 2019.

[17] H. Thapliyal, "Internet of things-based consumer electronics: reviewing existing consumer electronic devices, systems, and platforms and exploring new research paradigms," IEEE Consumer Electronics Magazine, vol. 7, no. 1, pp. 66-67, 2017.

[18] C. Wang, F. Sun, and L. Yang, "Research on multi-algorithm intelligent monitoring system based on internet of things," Application of Electronic Technology, vol. 43, no. 11, p. 4, 2017.

[19] L. Sánchez, J. Lanza, and L. Muoz, "From the internet of things to the social innovation and the economy of data," Wireless Personal Communications, vol. 113, no. 3, pp. 1407-1421, 2020.

[20] H. Zhu, L. Yang, Q. Zhu, and N. Chen, "Intelligent collaborative wireless access network and its key technologies in the edge service environment of the internet of things," Journal of Nanjing University of Posts and Telecommunications: Natural Science Edition, vol. 40, no. 5, p. 14, 2020.

[21] C. Garrido-Hidalgo, F. J. Ramirez, T. Olivares, and L. Sanchez, "The adoption of Internet of things in a circular supply Chain framework for the recovery of WEEE: the case of Lithium-ion electric vehicle battery packs," Waste Management, vol. 103, no. 32, p. 44, 2020.

[22] D. Li, C. Peng, and X. Lei, "The impact of dynamic capabilities on the synergy of dual innovation: the moderating effect of environmental competitiveness," Operations Research and Management, vol. 26, no. 9, pp. 183-192, 2017.

[23] R. C. Jason, C. Sadie, and D. David, "Security risk assessment in internet of things systems," IT Professional, vol. 19, no. 5, pp. 20-26, 2017.

[24] E. Ngai, F. Dressler, V. Leung, and M. Li, "Guest editorial special section on internet-of-things for smart cities and urban informatics," IEEE Transactions on Industrial Informatics, vol. 13, no. 2, pp. 748-750, 2017.

[25] Y. Shao and W. Lu, "Research on the collaborative innovation and integration of China's internet of things industry led by telecom operators," Chinese Journal of Management, vol. 13, no. 2, p. 9, 2016.

[26] F. Gianni, S. Mora, and M. Divitini, "RapIoT toolkit: rapid prototyping of collaborative internet of things applications," Future Generation Computer Systems, vol. 95, no. 6, pp. 867-879, 2019.

[27] G. Hatzivasilis, K. Fysarakis, O. Soultatos, I. Askoxylakis, I. Papaefstathiou, and G. Demetriou, "The industrial internet of things as an enabler for a Circular Economy Hy-LP: a novel IIoT protocol, evaluated on a wind park'," Computer Communications, vol. 119, no. 4, pp. 127-137, 2018.

[28] J. Yang and W. Zhang, "Mobile high-dimensional abnormal data automatic mining simulation in the internet of things environment," Computer Simulation, vol. 35, no. 1, p. 4, 2018.

[29] J. Schultz, "The internet of things we don'," Communications of the ACM, vol. 59, no. 5, pp. 36-38, 2016. 